\title{
Growth of Chrysanthemum in Response to Supplemental Light Provided by Irregular Light Breaks during the Night
}

\author{
Katrine Heinsvig Kjaer ${ }^{1}$ and Carl-Otto Ottosen \\ Department of Horticulture, Aarhus University, Kirstinebjergvej 10, 5792 Aarslev, Denmark
}

\begin{abstract}
Additional INDEX words. circadian rhythm, leaf expansion, stem elongation, chlorophyll content, chlorophyll fluorescence, carbohydrates

ABstract. Circadian rhythms are believed to be of great importance to plant growth and performance under fluctuating climate conditions. However, it is unclear how plants with a functioning circadian clock will respond to irregular light environments that disturb circadian-regulated parameters related to growth. Chrysanthemum (Chrysanthemum morifolium 'Coral Charm') was exposed to supplemental light provided as irregular light breaks during the night, achieved by controlling the light based on forecasted solar irradiance and electricity prices. Growth, in terms of carbon gain, was linearly correlated to both daylength and daily light integral. This response was observed irrespective of the irregularity of the light breaks and despite circadian-regulated processes of carbohydrate metabolism, chlorophyll fluorescence, and leaf chlorophyll content being affected. Leaf expansion and stem elongation occurred at a faster rate in plants grown in short days with irregular light breaks during the night period compared with plants grown in a climate with a consecutive long light period, showing that low average light intensity promoted expansion of the photosynthetic area of the plants. These results are important to gain an understanding of the relationship between circadian-regulated processes and plant growth. These results will also contribute to increased energy savings in the use of supplemental light in greenhouse production.
\end{abstract}

Protected plant production systems at northern latitudes largely rely on the use of supplemental light to extend the number of light hours during the day and subsequently the light integral (Markvart et al., 2009). However, because the electricity prices vary on an hourly basis, an economical optimization of supplemental light depends both on the photosynthetic efficiency of the light and on the cost of the light. In a recently developed low-energy input system for optimal use of supplemental light, it was recommended that light should be turned on only when energy prices are low and turned off in peak load periods in the afternoon and in the morning (Markvart et al., 2009). Consequently, the daily light hours did not occur consecutively, but were instead split into periods of solar irradiance potentially combined with supplemental light during the day and a night period interrupted by irregular light breaks (NB lighting). The light breaks depended on the selected set points for photosynthesis and forecasted solar irradiance; thus, the light breaks were not identical between nights. The overall result was a light pattern that was very irregular.

Plants are adapted to sense daylength to schedule developmental events to coincide with particular environmental conditions, i.e., flower induction (Jackson, 2009). This sensing is based on the circadian clock, which has evolved as an endogenous 24-h oscillator that is present for most biochemical and physiological processes, i.e., $\mathrm{CO}_{2}$ assimilation, carbohydrate metabolism, nitrogen assimilation, and plant growth (Harmer et al., 2000; Kreps and Kay, 1997; Nozue and Maloof, 2006; Walter et al., 2009). The rhythm of these plant circadian-regulated processes

Received for publication 16 Aug. 2010. Accepted for publication 15 Oct. 2010. This work was supported by the Ministry of Food, Agriculture and Fisheries, Denmark.

We thank Ruth Nielsen and Connie Damgaard for great support in the propagation and maintenance of the plants and technical assistance.

${ }^{1}$ Corresponding author. E-mail: katrine.kjaer@agrsci.dk. is synchronized to a 24-h cycle by external cues, called "zeitgebers" (time givers), the primary one being light and the secondary one being temperature (Bünning, 1967; Rensing and Ruoff, 2002). Studies have shown that plants with a clock period corresponding to the environment performed better than plants with circadian clocks differing from the actual environment (Dodd et al., 2005). However, it is unknown how plants with a functioning circadian clock respond to an environment with irregular NB lighting.

Long-day (LD) treatments in which the day was extended by supplemental light frequently promoted an increase in plant dry weight (DW) in comparison with plants grown in short days, even when the light integral was the same (Adams and Langton, 2005). Furthermore, total plant DW and overall photosynthesis were the same irrespective of the LD given as an extension of the day or by NB lighting (Aung and Austin, 1971; Markvart et al., 2009). In other studies, NB lighting proved to be less effective in improving plant growth than LD conditions obtained by extending the light period with supplemental light (Hurd, 1973; Langton et al., 2003; Tafazoli and Vince-Prue, 1978). This shows that the specific timing of supplemental light to achieve increased growth rates is important but that this is likely to differ between species.

The rate of starch synthesis in plant leaves is inversely related to daylength (Chatterton and Silvius, 1979; Lorenzen and Ewing, 1992) and some plants are able to sense daylength and shift their starch accumulation pattern during the day and starch degradation during the night within a 24-h cycle when they experience a new daylength (Gibon et al., 2004; Lu et al., 2005). Altered carbohydrate metabolism, in turn, leads to instantaneous and often very specific growth reactions in plants (Gibon et al., 2009; Sulpice et al., 2009; Wiese et al., 2007), and it was suggested that irregular light periods will disrupt the carbohydrate balance. 
The aim of this study was to identify how irregular light periods affect plant growth and carbohydrate metabolism of chrysanthemum plants. It was hypothesized that the irregular changes in the distribution and length of NB lighting periods would disturb the circadian rhythm of the light-regulated processes and decrease plant growth (Dodd et al., 2005; Resco et al., 2009). Differences in daylength, light distribution, and light integrals between treatments also made it possible to analyze the effect of daylength versus daily light integral (DLI) on plant growth parameters and starch metabolism.

\section{Materials and Methods}

Plant material and growth conditions. A total of 300 cuttings of $C$. morifolium 'Coral Charm' were rooted in pots containing peat (11 cm diameter) and grown in LD conditions (19 h light) for 2 weeks from 28 Sept. 2009 to 12 Oct. 2009. Then the plants were pinched back to three leaves and randomly distributed in two greenhouse compartments with similar set points for temperature and $\mathrm{CO}_{2}$ concentration. The experiment took place between 12 Oct. and 9 Nov. 2009. During the experimental period, the set point for $\mathrm{CO}_{2}$ was $700 \mu \mathrm{L} \cdot \mathrm{L}^{-1}$ during the light periods (day or supplemental light); the base temperature was $15^{\circ} \mathrm{C}$ with additions of $+10{ }^{\circ} \mathrm{C}$ during daytime and additionally $+5{ }^{\circ} \mathrm{C}$ during high light conditions reaching a maximum of $30{ }^{\circ} \mathrm{C}$ on warm sunny days. Supplemental light provided $60 \mu \mathrm{mol} \cdot \mathrm{m}^{-2} \cdot \mathrm{s}^{-1}$ at table level by high-pressure sodium lamps (SON-T agro, $600 \mathrm{~W}$; Phillips, Eindhoven, The Netherlands).

Plants were fertigated by flooding for $20 \mathrm{~min}$ every second day with nutrient solution consisting of $5.7 \mathrm{mM} \mathrm{NaNO}_{3}, 12.6 \mathrm{~mm}$ $\mathrm{NH}_{4} \mathrm{NO}_{3}, 8.9 \mathrm{~mm} \mathrm{KCl}, 0.7 \mathrm{~mm}$ Fe-EDTA, $47.6 \mathrm{~mm} \mathrm{KNO}_{3}$, $0.4 \mathrm{~mm}\left(\mathrm{NH}_{4}\right)_{2} \mathrm{SO}_{4}, 3.4 \mathrm{~mm}\left(\mathrm{NH}_{4}\right) \mathrm{H}_{2} \mathrm{PO}_{4}, 2.6 \mathrm{~mm} \mathrm{KH}_{2} \mathrm{PO}_{4}$, $5.8 \mathrm{mM} \mathrm{MgSO}_{4}$, and micronutrients. The two compartments were further divided into two subcompartments to run a total of four treatments with different light settings. The supplemental light control strategy was the same for three of the treatments, whereas in the fourth treatment, an additional light treatment of incandescent light was applied for $19 \mathrm{~h}$ every day. Results are only presented for the three treatments in which incandescent light was not applied. The light settings in these three treatments were based on a leaf photosynthesis model that calculated maximum photosynthesis at a given light intensity as a function of leaf temperature and $\mathrm{CO}_{2}$ concentration (Aaslyng et al., 2003; Lund et al., 2006). The set points were adjusted every $10 \mathrm{~min}$ based on actual irradiance and temperature in an attempt to optimize the $\mathrm{CO}_{2}$ level based on the leaf photosynthesis model, aiming to reach $80 \%$ of the maximal potential photosynthesis in the control treatment (LD) and $60 \%$ and $30 \%$ for the two other treatments $(60 \%$ NB and $30 \%$ NB), respectively. The NB refers to the light settings of these two treatments explained subsequently.

In the $30 \% \mathrm{NB}$ and $60 \% \mathrm{NB}$, the dark period was maintained from time of sunset (1700 HR) to $2000 \mathrm{HR}$; a software package (The Climate Monitor; University of Southern Denmark, Odense, Denmark) controlled the timing and use of supplemental light based on weather forecasts (irradiance) and realtime pricing of electricity. These data were obtained from the Danish Metrological Institute and Nord Pool (Nord Pool Spot, 2010) daily at $1800 \mathrm{HR}$. The supplemental light settings for the subsequent $24 \mathrm{~h}$ were optimized in two steps: 1) expected photosynthesis sum was calculated based on forecasted solar irradiance; and 2) if the set point for photosynthesis sum was not reached by solar irradiance, the software calculated the most price-efficient timing of using supplemental light based on the electricity prices.

In the LD treatment, the dark period was maintained from the time of sunset (1700 HR) to $2200 \mathrm{HR}$. At dusk, curtains were closed when the photosynthetic photon flux $(P P F)$ fell below $38 \mu \mathrm{mol} \cdot \mathrm{m}^{-2} \cdot \mathrm{s}^{-1}$ and supplemental light was turned on when the $P P F$ was below $198 \mu \mathrm{mol} \cdot \mathrm{m}^{-2} \cdot \mathrm{s}^{-1}$ from 2200 to $1600 \mathrm{HR}$.

Inside the greenhouse, light intensity, air temperature, relative humidity $(\mathrm{RH})$, and $\mathrm{CO}_{2}$ concentrations were recorded in each treatment just above the plant canopy. Additionally, the state of supplemental light (on or off) was recorded. The PPF was recorded at a weather station above the greenhouse, and the light transmission factor of the greenhouse (0.5) was used to calculate the light intensity $\left(\mu \mathrm{mol} \cdot \mathrm{m}^{-2} \cdot \mathrm{s}^{-1}\right)$ inside the greenhouse. The DLI of supplemental light $\left(\mu \mathrm{mol} \cdot \mathrm{m}^{-2} \cdot \mathrm{s}^{-1}\right)$ was calculated by adding DLI of supplemental light to the DLI of PPF. Furthermore, the cumulative light integral (CLI), the cumulative number of light hours $(\mathrm{CLH})$, and the cumulative number of light periods were calculated for each week.

Growth MEASUREMENTS. The pinched plants developed three lateral stems. Every week, six plants from each treatment were randomly selected and destructively harvested for growth measurements. The stem length was measured as the total length of the first basipetally stem. The leaves were separated from lateral stems and counted, and leaf area was measured using a leaf area meter (LI-3000; LI-COR, Lincoln, NE). Fresh weight of leaf and stem material was determined, plant material was dried at $70{ }^{\circ} \mathrm{C}$ for $24 \mathrm{~h}$, and DW was subsequently determined.

Five plants in each treatment were randomly selected on Day 1 for leaf growth measurements. These plants were marked with white plastic clips on each of two leaves positioned as the second unfolded leaf on two lateral stems. The leaf length, from petiole to leaf tip, and the leaf width were measured manually every third day during the 27-d growth period to follow the expansion of single leaves from the start of unfolding to maturity. A rank-specific leaf form factor (0.51) was used to calculate leaf area from the leaf dimensions (length $\times$ width $\times$ form factor $=$ area). The rank specific leaf form factor was determined by harvesting and analyzing 30 chrysanthemum leaves of different sizes. The length and width of these leaves were measured and related to leaf area that was measured with the leaf area meter (LI-3000).

Physiology and Carbohydrate measurements. Every week, the day before harvest, and immediately before the start of the dark period, six plants from each treatment were randomly selected for carbohydrate determinations. Leaf disks ( $7 \mathrm{~mm}$ diameter) were sampled from the interveinal tissue of the tip of the two uppermost positioned fully developed leaves on each plant. After sampling, the leaf disks were frozen in liquid nitrogen and stored at $-80{ }^{\circ} \mathrm{C}$ for further extraction.

Before extraction of soluble carbohydrates, leaf disks were freeze-dried, weighed, and ground in a mixer mill (MM200; Retsch, Haan, Germany) with a stainless steel ball $(7 \mathrm{~mm}$ diameter). The soluble sugars (glucose, fructose, and sucrose) were extracted with $80 \%$ ethanol and $5 \mathrm{~mm}$ HEPES until the leaf material appeared pale. The sugar concentrations were measured by a coupled enzyme assay, in which the reaction from $\mathrm{NADP}^{+}$to $\mathrm{NADPH}+\mathrm{H}^{+}$was detected quantitatively (Jones et al., 1977; Walter et al., 2002) using a multidetection microplate reader (Synergy ${ }^{\mathrm{TM}} 2$; BioTek Instruments, Vinooski, 
VT). The extracted and pale leaf material was prepared for starch analysis by gelatinization in an autoclave at $120^{\circ} \mathrm{C}$ for $90 \mathrm{~min}$ and incubated with Na-acetate buffer containing amyloglucosidase and $\alpha$-amylase for $16 \mathrm{~h}$. The starch concentration was determined enzymatically as glucose equivalents by the enzymatic assay described previously.

The chlorophyll content was measured on two of the uppermost positioned fully developed leaves on five plants from each treatment at 1000 HR using a portable chlorophyll meter (Minolta SPAD-502; Spectrum Technologies, Plainfield, IL). The readings from this meter are linearly related to the concentration of extractable chlorophyll per unit leaf area (Schaber and Chacko, 1991).

Immediately after measuring leaf chlorophyll content, five leaves from randomly selected individual plants were darkadapted for $30 \mathrm{~min}$ with leaf clips to determine the dark-adapted values of initial fluorescence $\left(\mathrm{F}_{\mathrm{o}}\right)$ and maximum fluorescence $\left(\mathrm{F}_{\mathrm{m}}\right)$ with a 1-s saturating flash $\left(P P F\right.$ less than $\left.8000 \mu \mathrm{mol} \cdot \mathrm{m}^{-2} \cdot \mathrm{s}^{-1}\right)$ using a chlorophyll fluorescence meter (MiniPam; Heinz Walz, Eifeltrich, Germany). Each measurement was repeated $30 \mathrm{~min}$ later, and the maximum quantum efficiency of PSII $\left(\Phi_{\mathrm{PSII}}\right)$ was calculated as: $F_{v} / F_{m}=\left(F_{m}-F_{o}\right) / F_{m}$ (Maxwell and Johnson, 2000).

Statistical analysis. Statistical analyses were carried out using the R-language "stat" package, release 2.10.0 (R Foundation for Statistical Computing, 2010). Climatic data were extracted from the environmental climate computer and values of means, maximum, minimum, sum, and SDS of $P P F$, hours of light, and number of light periods were calculated in relation to day, week, and treatment using the SummaryBy work package of R-language (doBy). The effect of time and treatment on weekly means of climatic parameters and harvest data of plant morphology, leaf carbohydrate contents, chlorophyll contents, and $\Phi_{\mathrm{PSII}}$ was analyzed by a generalized linear model allowing for nested random effects (GLM function). Means of the different treatments were separated by a pairwise $t$ test using the Holm correction (95\% confidence intervals). A multiple regression analysis was performed by fitting a linear model to the morphological data allowing the interaction between treatment and either CLH or CLI using the LM function. A multiple regression analysis was also performed on the starch data allowing for the interaction between week and either DLI or daylength (DL).

\section{Results}

Cuimate. As a result of low light irradiance levels, the dynamic components of the leaf photosynthesis model only induced minor differences in daily means of $\mathrm{CO}_{2}$, temperature, and $\mathrm{RH}$ between the treatments. The average values per day for all treatments were $706 \pm 4.3 \mu \mathrm{L} \cdot \mathrm{L}^{-1} \mathrm{CO}_{2}, 19 \pm 2.9^{\circ} \mathrm{C}$, and $66.4 \% \pm 6.7 \%$ RH. During the $27 \mathrm{~d}$ from 12 Oct. 2009 to 8 Nov. 2009 , supplemental light was turned on each day on an average of $15.4 \pm 0.2 \mathrm{~h}$ in the LD treatment, $8.3 \pm 0.1 \mathrm{~h}$ in the $60 \% \mathrm{NB}$ treatment, and $3 \pm 0.1 \mathrm{~h}$ in the $30 \% \mathrm{NB}$ treatment. The differences in supplemental light resulted in large differences in both total daylength between treatments and between days for the $30 \% \mathrm{NB}$ and $60 \% \mathrm{NB}$ treatments (Fig. 1). The contribution of supplemental light to DLI was significantly lower in the $30 \%$ NB treatment in comparison with the LD treatment during the first 3 weeks and significantly lower in the $60 \%$ NB treatment in comparison with LD during the third week (Table 1). This resulted in a lower DLI in $30 \%$ NB in comparison with the two

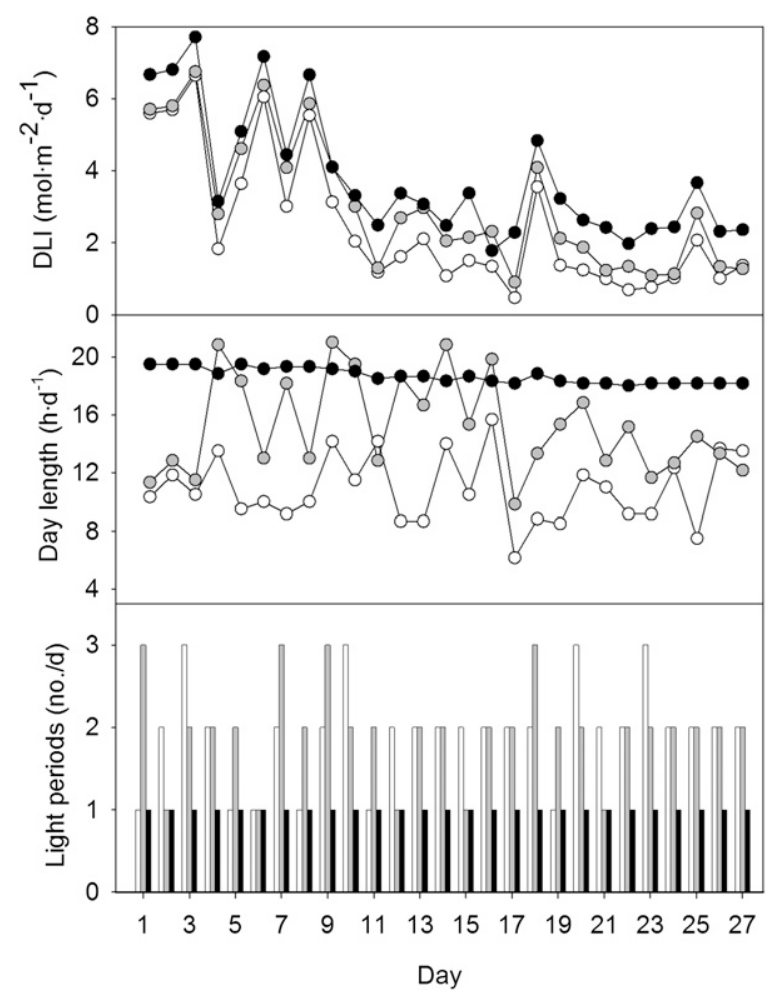

Fig. 1. Daily light integral (DLI), daylength, and number of light periods per day in three greenhouse treatments with different strategies for the use of supplemental light. Treatments were long day with a daylength of $\approx 19 \mathrm{~h}$ [LD (black circles, black bars)], 60\% NB (gray circles, grey bars), and 30\% NB (white circles, white bars), where the percentage value refers to set point for photosynthesis based on a leaf photosynthesis model and NB refers to irregular night breaks of light.

other treatments during Week 3 and in a difference in DLI among all treatments in Week 4 (Fig. 1).

The lower contribution of supplemental light to DLI in the $30 \% \mathrm{NB}$ and $60 \% \mathrm{NB}$ treatments resulted in a lower CLI in both treatments compared with the LD treatment (Table 1). The average light hours per week (daylength), in which hours of supplemental light and hours of daylight were included, was significantly different between all treatments, although similar in Week 2 for the LD and the $60 \% \mathrm{NB}$ treatment. The shorter daylength resulted in a lower CLH for both NB treatments in comparison with LD. Also, the number of light periods differed between the LD treatment and the two other treatments, but there was no difference between $30 \% \mathrm{NB}$ and $60 \% \mathrm{NB}$ during the last 2 weeks (Table 1; Fig. 1).

Plant growth and Physiology. During the first $21 \mathrm{~d}$, leaf expansion of the second unfolded leaf was similar in all three treatments (Fig. 2A). However, during the last $7 \mathrm{~d}$, these leaves expanded faster in the LD treatment, and after $27 \mathrm{~d}$, the leaves were significantly larger compared with the leaves at the same position in the NB treatments $(P<0.05)$. This result was not supported by a difference in total leaf area or number of leaves between treatments after 4 weeks, but the leaf area ratio (LAR) was increased for plants grown in the $30 \% \mathrm{NB}$ treatment indicating that leaves were thinner (Table 2).

The weekly increase in shoot DW, leaf area, and plant height was linearly correlated to CLH and CLI (Fig. 3). The slope of the correlation with respect to leaf area and plant height was significantly steeper for plants grown in the $30 \% \mathrm{NB}$ treatment 
Table 1. Climatic parameters in three greenhouse treatments with different strategies for the use of supplemental light. ${ }^{\mathrm{Z}}$

\begin{tabular}{|c|c|c|c|c|c|c|c|}
\hline Week & Treatment & $\begin{array}{l}\text { DLI }[\text { mean } \pm \text { SE } \\
\left.\left(\mathrm{mol} \cdot \mathrm{m}^{-2} \cdot \mathrm{d}^{-1}\right)\right]\end{array}$ & $\begin{array}{l}\mathrm{SL}[\text { mean } \pm \mathrm{SE} \\
(\% \mathrm{DLI})]\end{array}$ & $\begin{array}{c}\text { CLI } \\
\left(\mathrm{mol} \cdot \mathrm{m}^{-2} \cdot \text { week }^{-1}\right)\end{array}$ & $\begin{array}{c}\text { CLH } \\
\left(\mathrm{h} \cdot \mathrm{week}^{-1}\right)\end{array}$ & $\begin{array}{c}\text { CLP } \\
\text { (no./week) }\end{array}$ & $\begin{array}{c}\text { Day length } \\
{\left[\text { mean } \pm \mathrm{SE}\left(\mathrm{h} \cdot \mathrm{d}^{-1}\right)\right]}\end{array}$ \\
\hline \multirow[t]{2}{*}{$\overline{1}$} & LD & $5.8 \pm 0.6$ & $26.4 \pm 6.1 \mathrm{a}^{\mathrm{y}}$ & 41.0 & 136.5 & 7 & $19.5 \pm 0.2 \mathrm{a}$ \\
\hline & $60 \% \mathrm{NB}$ & $5.2 \pm 0.5$ & $16.0 \pm 7.4 \mathrm{a}$ & 36.1 & 106.0 & 12 & $15.1 \pm 1.5 \mathrm{~b}$ \\
\hline \multirow[t]{3}{*}{2} & LD & $3.6 \pm 0.5$ & $49.1 \pm 8.7 \mathrm{a}$ & 66.5 & 266.2 & 14 & $18.5 \pm 0.3 \mathrm{a}$ \\
\hline & $60 \% \mathrm{NB}$ & $3.1 \pm 0.6$ & $41.0 \pm 8.2 \mathrm{a}$ & 58.1 & 228.5 & 25 & $17.5 \pm 1.3 \mathrm{a}$ \\
\hline & $30 \% \mathrm{NB}$ & $2.4 \pm 0.6$ & $19.7 \pm 8.9 b$ & 49.1 & 156.0 & 28 & $11.6 \pm 0.9 b$ \\
\hline & $60 \% \mathrm{NB}$ & $2.1 \pm 0.4 \mathrm{a}$ & $49.7 \pm 11.2 \mathrm{~b}$ & 72.8 & 331.8 & 40 & $14.8 \pm 1.2 \mathrm{~b}$ \\
\hline & $30 \% \mathrm{NB}$ & $1.5 \pm 0.4 \mathrm{~b}$ & $27.6 \pm 10.9 \mathrm{c}$ & 59.6 & 228.5 & 40 & $10.4 \pm 1.2 \mathrm{c}$ \\
\hline \multirow[t]{3}{*}{4} & LD & $2.5 \pm 0.2 \mathrm{a}$ & $77.3 \pm 5.2$ & 104.4 & 522.0 & 28 & $18.2 \pm 0.3 \mathrm{a}$ \\
\hline & $60 \% \mathrm{NB}$ & $1.6 \pm 0.3 \mathrm{~b}$ & $59.1 \pm 11.8$ & 84.1 & 308.8 & 55 & $14.4 \pm 1.2 \mathrm{~b}$ \\
\hline & $30 \% \mathrm{NB}$ & $1.2 \pm 0.2 \mathrm{c}$ & $46.3 \pm 11.6$ & 67.9 & 432.3 & 52 & $11.5 \pm 1.1 \mathrm{c}$ \\
\hline
\end{tabular}

${ }^{z}$ Treatments were long day with a daylength of $\approx 19 \mathrm{~h}(\mathrm{LD}), 60 \% \mathrm{NB}$, and $30 \% \mathrm{NB}$, where the percentage value refers to set point for photosynthesis based on a leaf photosynthesis model and NB refers to irregular light breaks during night. Values of daily light integral (DLI), DLI of supplemental light (SL), and daylength are average values for each week. Values of cumulative light integral (CLI), cumulative light hours $(\mathrm{CLH})$, and cumulative number of light periods (CLP) are the sums for each week.

${ }^{\mathrm{y}}$ Different letters indicate significant difference in probability values between treatments within week $(P<0.05)$.
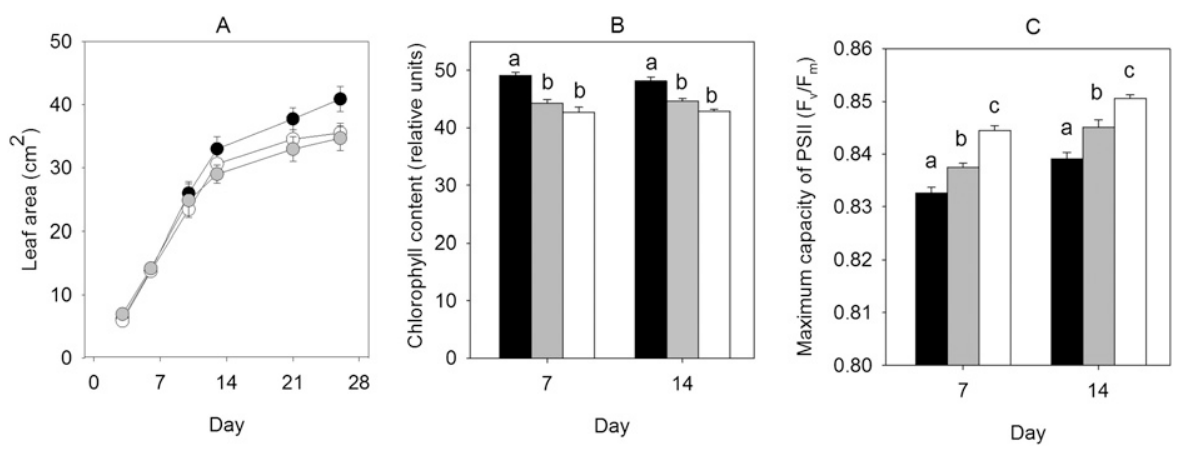

Fig. 2. Leaf expansion of individual leaves, leaf chlorophyll content, and maximum capacity of PSII $\left[\Phi_{\mathrm{PSII}}\left(\mathrm{F}_{\mathrm{v}} / \mathrm{F}_{\mathrm{m}}\right)\right]$ in chrysanthemum plants grown in treatments with different strategies for the use of supplemental light. Treatments were long day [LD (black circles, black bars)], $60 \% \mathrm{NB}$ (gray circles, grey bars), and $30 \% \mathrm{NB}$ (white circles, white bars) where the percentage value refers to set point for photosynthesis based on a leaf photosynthesis model and NB refers to irregular night breaks of light. (A) Leaf expansion of single leaves from unfolding to maturity. (B) Chlorophyll content in relative units shown for 2 representative days during the experiment. (C) Values of $\Phi_{\mathrm{PSII}}$ shown for two representative dates during the experiment. Values are mean values $( \pm \mathrm{SE})$ for each day. Different letters indicate significant difference in probability values between treatments $(P<0.05)$.

and in relation to CLH. This suggested that the shorter daylength (below $12 \mathrm{~h}$ ) or the lower average light intensity, which was a consequence of the shorter daylength, increased leaf expansion and stem elongation (Fig. 3). However, when the same parameters were related to CLI, there was no significant treatment effect, indicating that an interaction between daylength and average light intensity explained the differences between treatments.

Values of leaf chlorophyll content were significantly lower in the $30 \% \mathrm{NB}$ and $60 \% \mathrm{NB}$ compared with the LD treatment as illustrated for Day 7 and Day 14 (Fig. 2B). In contrast, $\Phi_{\text {PSII }}$ was slightly, but significantly, higher for plants grown in the $30 \% \mathrm{NB}$ treatment than for plants grown in the $60 \% \mathrm{NB}$ treatment and lowest for LD plants (Fig. 2C).

The leaf starch content measured at the end of the day (1700 HR) varied in relation to the developmental stage of the plants (Fig. 4A). The highest content of leaf starch was found at the second harvest in plants grown in the LD treatment. During this week, the starch content was significantly lower in the $30 \% \mathrm{NB}$ treatment but not in the $60 \% \mathrm{NB}$ treatment. A correlation was found between leaf starch content and daylength (Fig. $5)$. The leaf sucrose content decreased over time in all treatments (Fig. 4B) and was highest in the $60 \% \mathrm{NB}$ treatment and lowest in the $30 \%$ NB treatment. The fructose content was significantly higher in the $30 \%$ NB treatment than in the two other treatments, although there was no effect of treatment at the different harvest times (Fig. 4C). There was no effect of either treatment or harvest time on leaf glucose contents (Fig. 4D).

\section{Discussion}

Our results demonstrated that in vegetative chrysanthemums, plant dry matter production was related to light integral and light hours, although the supplemental light was provided as irregular NB lighting. These results are in accordance with those of Markvart et al. (2009), who showed that time-of-day lighting had a limited effect on the total carbon gain in chrysanthemums. These results confirm that climate control strategies based on hourly changes in electricity prices can have an economical value for vegetative production of plant material.

The present results further illustrated that irregular light periods disturb the circadian rhythm and induce changes in leaf expansion, leaf chlorophyll contents, and $\Phi_{\mathrm{PSII}}$. However, in the present research, these changes had only a limited effect on plant growth.

Leaf expansion and stem elongation occurred relatively faster in relation to cumulative light hours in the treatment with a daylength below $12 \mathrm{~h}$ in comparison with the two treatments with longer daylengths. This was seen although no differences in total leaf area and plant height were seen between this treatment and the two others at any harvest. In contrast, 
Table 2. Morphological parameters for chrysanthemum plants grown in three treatments with different strategies for the use of supplemental light. ${ }^{\mathrm{z}}$

\begin{tabular}{|c|c|c|c|c|c|c|}
\hline Week & Treatment & $\begin{array}{c}\text { Plant DW } \\
{[\text { mean } \pm \mathrm{SE}(\mathrm{g})]}\end{array}$ & $\begin{array}{c}\text { Plant ht } \\
{[\text { mean } \pm \mathrm{SE}(\mathrm{cm})]}\end{array}$ & $\begin{array}{c}\text { Total leaf area } \\
{\left[\text { mean } \pm \mathrm{SE}\left(\mathrm{cm}^{2}\right)\right]}\end{array}$ & $\begin{array}{c}\text { Leaves } \\
{[\text { mean } \pm \text { SE (no.) }]}\end{array}$ & $\begin{array}{c}\text { LAR } \\
{\left[\text { mean } \pm \mathrm{SE}\left(\mathrm{cm}^{2} \cdot \mathrm{g}^{-1}\right)\right]}\end{array}$ \\
\hline \multirow[t]{2}{*}{1} & LD & $2.76 \pm 0.6 \mathrm{a}^{\mathrm{y}}$ & $15.7 \pm 1.0$ & $483.7 \pm 76$ & $32.8 \pm 2.4 \mathrm{a}$ & $176 \pm 4 \mathrm{a}$ \\
\hline & $60 \% \mathrm{NB}$ & $2.06 \pm 0.9 \mathrm{~b}$ & $15.5 \pm 0.7$ & $424.5 \pm 37$ & $28.3 \pm 0.8 b$ & $206 \pm 4 b$ \\
\hline \multirow[t]{3}{*}{2} & LD & $4.55 \pm 0.3 \mathrm{a}$ & $19.8 \pm 1.2$ & $738.0 \pm 39$ & $37.5 \pm 3.2$ & $164 \pm 4 \mathrm{a}$ \\
\hline & $60 \% \mathrm{NB}$ & $3.76 \pm 0.2 \mathrm{a}$ & $20.9 \pm 0.4$ & $672.5 \pm 25$ & $34.3 \pm 1.3$ & $179 \pm 5 \mathrm{a}$ \\
\hline & $30 \% \mathrm{NB}$ & $2.96 \pm 0.1 \mathrm{~b}$ & $20.1 \pm 0.4$ & $633.8 \pm 16$ & $30.8 \pm 1.0$ & $216 \pm 6 b$ \\
\hline & $30 \% \mathrm{NB}$ & $4.88 \pm 0.3 b$ & $28.4 \pm 0.8$ & $889.4 \pm 44$ & $38.0 \pm 2.5 \mathrm{~b}$ & $216 \pm 6 b$ \\
\hline \multirow[t]{3}{*}{4} & LD & $8.69 \pm 0.4 \mathrm{a}$ & $37.8 \pm 0.7$ & $1274.3 \pm 26$ & $48.6 \pm 0.9$ & $147 \pm 5 \mathrm{a}$ \\
\hline & $60 \% \mathrm{NB}$ & $8.47 \pm 0.5 \mathrm{a}$ & $39.8 \pm 1.1$ & $1292.3 \pm 58$ & $50.2 \pm 3.7$ & $153 \pm 6 a$ \\
\hline & $30 \% \mathrm{NB}$ & $6.10 \pm 0.2 b$ & $36.1 \pm 0.6$ & $1161.8 \pm 32$ & $49.0 \pm 1.3$ & $194 \pm 6 b$ \\
\hline
\end{tabular}

${ }^{\mathrm{z}}$ Treatments were long day with a daylength of $\approx 19 \mathrm{~h}(\mathrm{LD}), 60 \% \mathrm{NB}$, and $30 \% \mathrm{NB}$, where the percentage value refers to set point for photosynthesis based on a leaf photosynthesis model and NB refers to irregular light breaks during night. Values of plant dry weight, plant height, total leaf area, number of leaves, and leaf area ratio per plant (LAR) are average values for each week.

${ }^{y}$ Different letters indicate significant difference in probability values between treatments within week $(P<0.05)$.

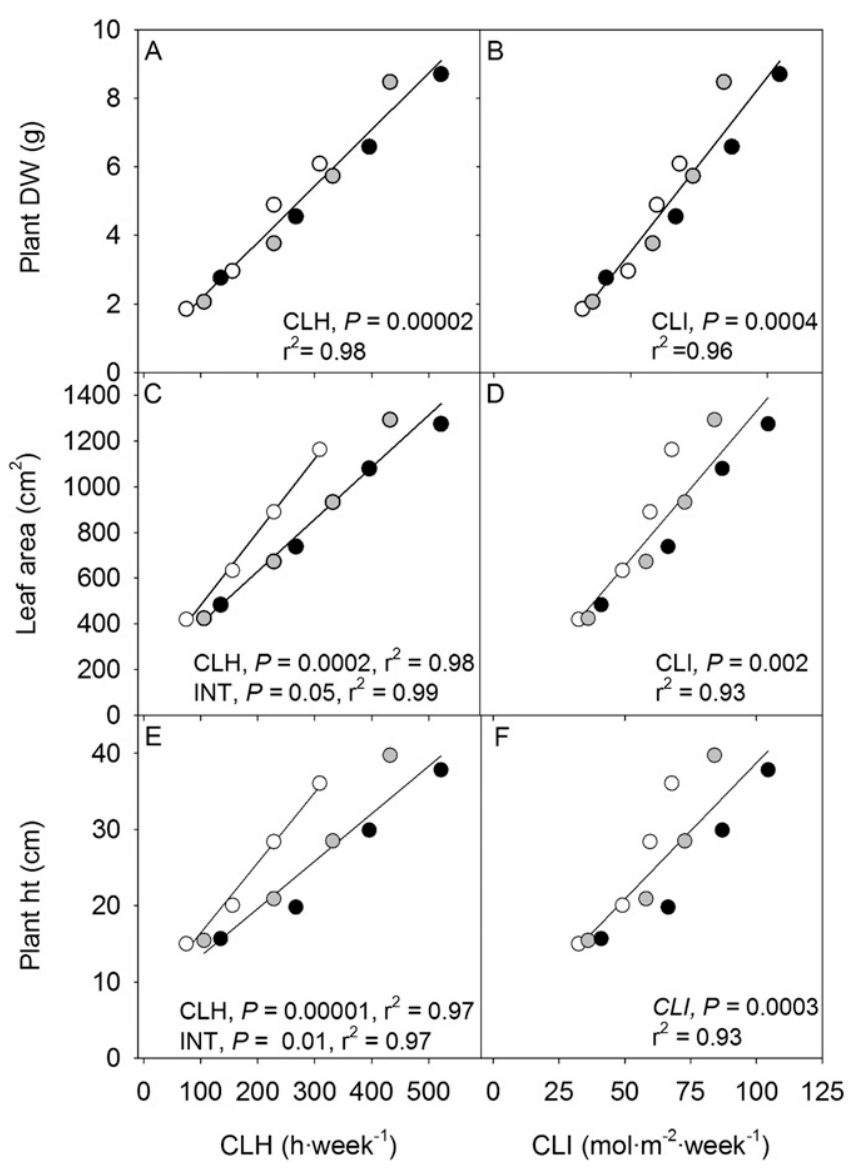

Fig. 3. Correlations between plant growth parameters and the cumulative number of light hours (CLH) or the cumulative light integral (CLI) in chrysanthemum plants grown in three different treatments. Treatments were long day [LD (black circles)], 60\% NB (gray circles), and 30\% NB (white circles) where the percentage value refers to set point for photosynthesis based on a leaf photosynthesis model and NB refers to irregular night breaks of light. (A-B) Plant dry weight, $(\mathbf{C}-\mathbf{D})$ total leaf area, and (E-F) plant height. Values are mean values for each week. Probability indicate statistical significance of CLH or CLI and the interaction with treatment. The slope of the $30 \% \mathrm{NB}$ treatment (INT) was significantly different from those for LD and $60 \% \mathrm{NB}$ so the regressions are shown separately. the LAR was significantly increased for the $30 \%$ NB plants, indicating that leaves were thinner, presumably as a response to increase the photosynthetic area of the plants grown under low light intensities and during the relatively short days. Large thin leaves are often seen on plants grown in LD conditions with low light intensities in comparison with plants grown in SD conditions with higher light intensities (Adams and Langton, 2005). Differences in leaf expansion rate in relation to changes in light intensity or daylength have to our knowledge not been reported before, although it could be suggested that the thin leaves may expand faster than thick leaves as a result of the formation of less cell layers. Leaf expansion and stem elongation occur in a diurnal pattern and are regulated by the circadian clock in several plant species (Nozue et al., 2007; Walter et al., 2002, 2009; Walter and Schurr, 2005; Wiese et al., 2007). Maximum growth rates are often observed during the night, suggesting that the longer night periods may increase the available time for maximum cell expansion rates. However, Bertram and Karlsen (1994) reported that changes in night length did not induce changes in stem elongation patterns in various plant species, although an increased number of long days was shown to increase final plant height in chrysanthemum (Carvalho and Heuvelink, 2003). Adams and Langton (2005) suggested that low average light intensity may increase leaf expansion and that not only the photosynthetic area, but also the photosynthetic efficiency per unit leaf area increase. In our experiment, increased leaf expansion was accompanied by a decrease in leaf chlorophyll content, possibly as a result of thinner leaves or diurnal variation in leaf chlorophyll content and increased $\Phi_{\text {PSII }}$. This supported that the plants responded to the average light intensity by increasing the photosynthetic area and the efficiency of the photosynthetic apparatus.

Lower leaf chlorophyll contents and increased $\Phi_{\mathrm{PSII}}$ coincided with slightly lower growth rates of single leaves at the same position for plants grown in the NB treatments. However, because values of both chlorophyll content and $\Phi_{\mathrm{PSII}}$ were relatively high in plants from all treatments, these parameters were not considered to affect the actual growth rates. The values of $\Phi_{\mathrm{PSII}}$ ranged from 0.83 to 0.86 , which is close to the 


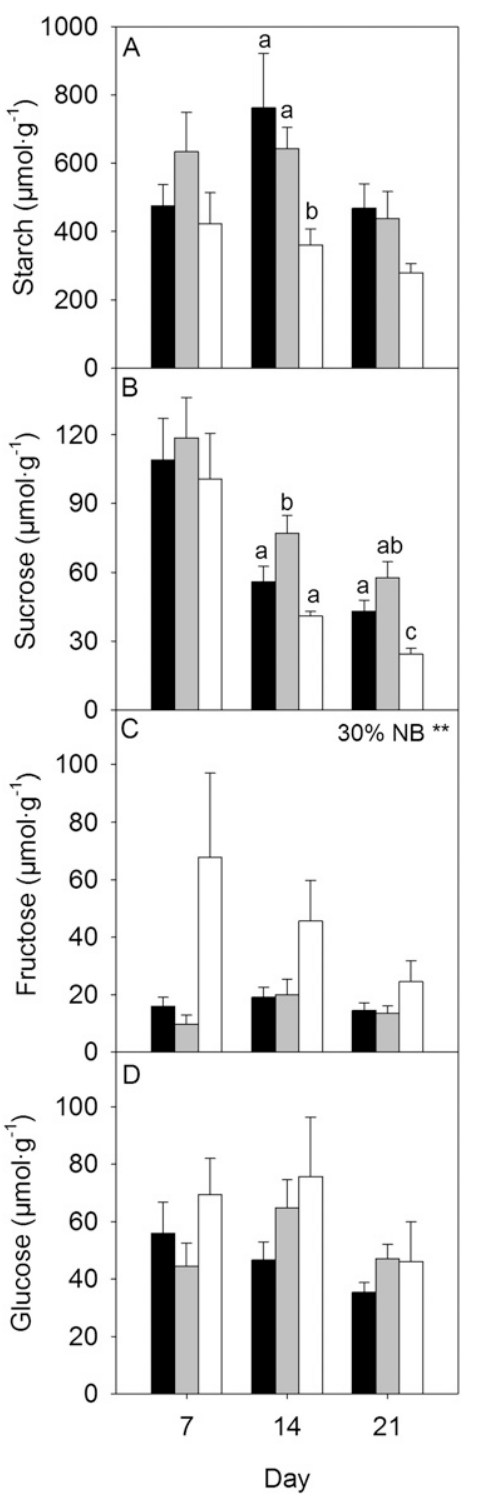

Fig. 4. Leaf content of starch and sugars in chrysanthemum plants at the end of the day (1700 HR) on three harvest dates (Days 7, 14, and 21) in three treatments with different strategies for the use of supplemental light. Treatments are long day [LD (black bars)], $60 \% \mathrm{NB}$ (gray bars), and 30\% NB (white bars), where the percentage value refers to set point for photosynthesis based on a leaf photosynthesis model and NB refers to irregular night breaks of light. (A) Starch, (B) sucrose, (C) fructose, and (D) glucose. Values are means ( \pm SE) for each day. Different letters indicate significant difference in probability values between treatments within days $(P<0.05) ; *$ Significant difference between treatments $(P<0.001)$

optimal values of 0.83 for a range of plant species (Johnson et al., 1993).

Although the lower leaf chlorophyll contents could have been the result of thinner leaves, a decrease in leaf chlorophyll has earlier been shown for plants grown in conditions in which light-dark cycles were unmatched to the endogenous circadian clock period of $24 \mathrm{~h}$ in plant mutants (Dodd et al., 2005) and in wild-type plants in short-day conditions (Hurd, 1973; Langton et al., 2003). Despite the lower chlorophyll contents measured in the chrysanthemum leaves in both NB treatments, increased $\mathrm{F}_{\mathrm{v}} / \mathrm{F}_{\mathrm{m}}$ values indicated a significant increase in $\Phi_{\mathrm{PSII}}$ in relation to the shorter daylengths and lower DLI. $\mathrm{F}_{\mathrm{v}} / \mathrm{F}_{\mathrm{m}}$ values are

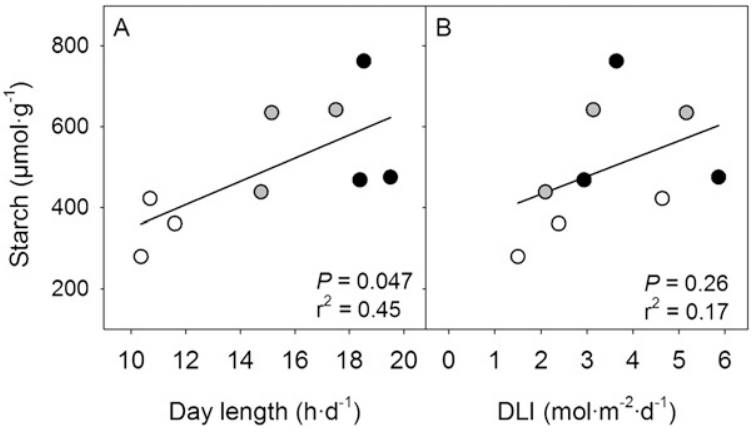

Fig. 5. Correlations between leaf starch content and daylength or daily light integral (DLI) for chrysanthemum plants grown in three treatments with different strategies for the use of supplemental light. Treatments were long day [LD (black circles)], 60\% NB (gray circles), and 30\% NB (white circles), where the percentage value refers to set point for photosynthesis based on a leaf photosynthesis model and NB refers to irregular night breaks of light. Data are from three harvest dates (Days 7, 14, and 21). Values are mean for each day. Probability values indicate statistical significance of the correlation between leaf starch and daylength or DLI.

highest in the morning and reach a minimum at midday as a result of natural photoinhibition both in high light (Kao and Forseth, 1992; Long et al., 1994) and in low light (van der Boogaard et al., 2001). Therefore, it is suggested that the time of measurement also affected the differences found in leaf chlorophyll content and $\mathrm{F}_{\mathrm{v}} / \mathrm{F}_{\mathrm{m}}$ because plants from the different treatments may have been exposed to light for a different amount of time before they were measured.

A correlation between leaf starch contents and daylength was determined across treatments, which supports the work of Gibon et al. (2009) demonstrating a clear correlation between daily leaf starch accumulation and daylength in Arabidopsis thaliana. In our study, daylength varied between all treatments, whereas DLI only differed for the $30 \% \mathrm{NB}$ treatment; therefore, our results indicate that daylength is a more important factor for daily starch accumulation than DLI. An effect of DLI on starch accumulation in different plants has previously been reported (Mattson et al., 2008; van Labeke et al., 2001). However, in these studies, differences in DLI corresponded to differences in daylength, which was not the case in our study.

Flowering in chrysanthemum plants was accompanied by increased fructose levels in leaves (K.H. Kjaer, I.M. Hannson, K. Thorup-Kristensen, E. Rosenqvist, and J.M. Aaslyng, unpublished results), which was also the case for plants grown in the treatment with an average daylength below $12 \mathrm{~h}$. Although no flower induction was observed in the chrysanthemum plants at any time, the altered carbohydrate composition with increased fructose and decreased sucrose levels may illustrate an integrated response of the plants in preparation to flowering, although flowering was not possible in the short-day plant chrysanthemum because of the light interruptions during the night.

\section{Conclusion}

Our results are the first to demonstrate that splitting a LD light period into a natural light period plus irregular NB lighting does not affect vegetative dry matter production in chrysanthemums. This finding highlights a plasticity of plants to irregular light periods and demonstrates that studying the diurnal 
activities in plant growth parameters in dynamic environments is an important tool to increase the understanding of the relationship between plant growth and circadian-regulated processes.

\section{Literature Cited}

Aaslyng, J.M., J.B. Lund, N. Ehler, and E. Rosenqvist. 2003. IntelliGrow: A greenhouse component-based climate control system. Environ. Model. Softw. 18:657-666.

Adams, S.R. and F.A. Langton. 2005. Photoperiod and plant growth: A review. J. Hort. Sci. Biotechnol. 80:2-10.

Aung, L.H. and M.E. Austin. 1971. Vegetative and reproductive responses of Lycopersicon esculentum Mill. to photoperiods. J. Expt. Bot. 22:906-914.

Bertram, L. and P. Karlsen. 1994. A comparison study on stem elongation of several greenhouse plants. Sci. Hort. 59:265-274.

Bünning, E. 1967. The physiological clock. Springer Verlag, Berlin, Germany.

Carvalho, S.M.P. and E. Heuvelink. 2003. Effect of assimilate availability on flower characteristics and plant height of cut chrysanthemum: An integrated study. J. Hort. Sci. Biotechnol. 78:711720 .

Chatterton, N.J. and J.E. Silvius. 1979. Photosynthate partitioning into starch in soybean leaves.1. Effects of photoperiod versus photosynthetic period duration. Plant Physiol. 64:749-753.

Dodd, A.N., N. Salathia, A. Hall, E. Kevei, R. Toth, F. Nagy, J.M. Hibberd, A.J. Millar, and A.A.R. Webb. 2005. Plant circadian clocks increase photosynthesis, growth, survival, and competitive advantage. Science 309:630-633

Gibon, Y., O.E. Blasing, N. Palacios-Rojas, D. Pankovic, J.H.M. Hendriks, J. Fisahn, M. Hohne, M. Gunther, and M. Stitt. 2004. Adjustment of diurnal starch turnover to short days: Depletion of sugar during the night leads to a temporary inhibition of carbohydrate utilization, accumulation of sugars and post-translational activation of ADP-glucose pyrophosphorylase in the following light period. Plant J. 39:847-862.

Gibon, Y., E.T. Pyl, R. Sulpice, J.E. Lunn, M. Hohne, M. Gunther, and M. Stitt. 2009. Adjustment of growth, starch turnover, protein content and central metabolism to a decrease of the carbon supply when arabidopsis is grown in very short photoperiods. Plant Cell Environ. 32:859-874.

Harmer, S.L., L.B. Hogenesch, M. Straume, H.S. Chang, B. Han, T. Zhu, X. Wang, J.A. Kreps, and S.A. Kay. 2000. Orchestrated transcription of key pathways in arabidopsis by the circadian clock. Science 290:2110-2113.

Hurd, R.G. 1973. Long-day effects on growth and flower initiation of tomato plants in low light. Ann. Appl. Biol. 73:221-228.

Jackson, S.D. 2009. Plant responses to photoperiod. New Phytol. 181:517-531.

Johnson, G.N., A.J. Young, J.D. Scholes, and P. Horton. 1993. The dissipation of excess excitation-energy in British plant-species. Plant Cell Environ. 16:673-679.

Jones, M.G.K., W.H. Outlaw, and O.H. Lowry. 1977. Enzymatic assay of $10^{-7}$ to $10^{-14}$ moles of sucrose in plant tissues. Plant Physiol. 60: 379-383.

Kao, W.Y. and I.N. Forseth. 1992. Diurnal leaf movement, chlorophyll fluorescence and carbon assimilation in soybean grown under different nitrogen and water availabilities. Plant Cell Environ. 15:703710 .

Kreps, J.A. and S.A. Kay. 1997. Coordination of plant metabolism and development by the circadian clock. Plant Cell 9:1235-1244.

Langton, F.A., S.R. Adams, and K.E. Cockshull. 2003. Effects of photoperiod on leaf greenness of four bedding plant species. J. Hort. Sci. Biotechnol. 78:400-404.

Long, S.P., S. Humphries, and P.G. Falkowski. 1994. Photoinhibition of photosynthesis in nature. Annu. Rev. Plant Physiol. Plant Mol. Biol. 45:633-662
Lorenzen, J.H. and E.E. Ewing. 1992. Starch accumulation in leaves of potato (Solanum-tuberosum L.) during the $1^{\text {st }} 18$ days of photoperiod treatment. Ann. Bot. (Lond.) 69:481-485.

Lu, Y., J.P. Gehan, and T.D. Sharkey. 2005. Daylength and circadian effects on starch degradation and maltose metabolism. Plant Physiol. 138:2280-2291.

Lund, J.B., A. Andreassen, C.O. Ottosen, and J.M. Aaslyng. 2006. Effect of a dynamic climate on energy consumption and production of Hibiscus rosa-sinensis L. in greenhouses. HortScience 41:384388.

Markvart, J., E. Rosenqvist, H. Sorensen, C.O. Ottosen, and J.M. Aaslyng. 2009. Canopy photosynthesis and time-of-day application of supplemental light. HortScience 44:1284-1290.

Mattson, N.S., J.H. Lieth, and W.-S. Kim. 2008. Temporal dynamics of nutrient and carbohydrate distribution during crop cycles of Rosa spp. 'Kardinal' in response to light availability. Sci. Hort. 118:246254

Maxwell, K. and G.N. Johnson. 2000. Chlorophyll fluorescence-A practical guide. J. Expt. Bot. 51:659-668.

Nord Pool Spot. 2010. System price. 26 Oct. 2010. <http://www. nordpoolspot.com/reports/systemprice $>$.

Nozue, K., M.F. Covington, P.D. Duek, S. Lorrain, C. Fankhauser, S.L. Harmer, and J.N. Maloof. 2007. Rhythmic growth explained by coincidence between internal and external cues. Nature 448:358366.

Nozue, K. and J.N. Maloof. 2006. Diurnal regulation of plant growth. Plant Cell Environ. 29:396-408.

R Foundation for Statistical Computing. 2010. The comprehensive R archive network. 26 Oct. 2010. <http://mirrors.dotsrc.org/cran/>.

Rensing, L. and P. Ruoff. 2002. Temperature effect on entrainment, phase shifting, and amplitude of circadian clocks and its molecular bases. Chronobiol. Int. 19:807-864.

Resco, V., J. Hartwell, and A. Hall. 2009. Ecological implications of plants' ability to tell the time. Ecol. Lett. 12:583-592.

Schaber, H. and E.K. Chacko. 1991. Relation between extractable chlorophyll and portable chlorophyll meter readings in leaves of 8 tropical and subtropical fruit-tree species. J. Plant Physiol. 138:674677.

Sulpice, R., E.T. Pyl, H. Ishihara, S. Trenkamp, M. Steinfath, H. Witucka-Wall, Y. Gibon, B. Usadel, F. Poree, M.C. Piques, M. Von Korff, M.C. Steinhauser, J.J.B. Keurentjes, M. Guenther, M. Hoehne, J. Selbig, A.R. Fernie, T. Altmann, and M. Stitt. 2009. Starch as a major integrator in the regulation of plant growth. Proc. Natl. Acad. Sci. USA 106:10348-10353.

Tafazoli, E. and D. Vince-Prue. 1978. A comparison of the effects of long days and exogenous growth regulators on growth and flowering in strawberry, Fragaria $\times$ ananassa Duch. J. Hort. Sci. 53:255-259. van der Boogaard, R., J. Harbinson, M. Mensink, and J. Ruijsch. 2001. Effects of quantity and daily distribution of irradiance on photosynthetic electron transport and $\mathrm{CO}_{2}$ fixation in tomato. Proc. 12th Intl. Congr. Photosyn. p. 28-30.

van Labeke, M.C., P. Dambre, M. Bodson, and H. Pien. 2001. Developmental changes in carbohydrate content in young rose shoots (Rosa hybrida 'Frisco'). Acta Hort. 547:193-201.

Walter, A., R. Feil, and U. Schurr. 2002. Restriction of nyctinastic movements and application of tensile forces to leaves affects diurnal patterns of expansion growth. Funct. Plant Biol. 29:1247-1258.

Walter, A. and U. Schurr. 2005. Dynamics of leaf and root growth: Endogenous control versus environmental impact. Ann. Bot. (Lond.) 95:891-900

Walter, A., W.K. Silk, and U. Schurr. 2009. Environmental effects on spatial and temporal patterns of leaf and root growth. Annu. Rev. Plant Biol. 60:279-304.

Wiese, A., M.M. Christ, O. Virnich, U. Schurr, and A. Walter. 2007. Spatio-temporal leaf growth patterns of Arabidopsis thaliana and evidence for sugar control of the diel leaf growth cycle. New Phytol. 174:752-761. 